\title{
Cirrhosis of liver: demographic and virological profile with emphasis on mode of transmission among patients presenting in a tertiary care hospital of Bangladesh
}

\author{
Mamoon AA ${ }^{a^{*}}$, Mahmud A ${ }^{*}$, Hossain RMMc ${ }^{c}$, Ahmed Sd, Sajjad SM"e, Bhuiyan TM ${ }^{f}$
}

\begin{abstract}
Background: Cirrhosis of liver is one of the important cause of liver disease in our country. Worldwide as well as in our country the most common cause of liver cirrhosis is due to hepatitis $B$ virus (HBV) and hepatitis $C$ virus (HCV) infection. Many of the patients with cirrhosis of liver do not know that they have already been affected with this kind of viral induced liver disease. They do not know how it occurs and what to be done afterwards due to lack of adequate knowledge with awareness and lack of proper guidance by the general physicians. The aim of our study is to see the demographic and virological profiles of cirrhosis of liver with their possible modes of transmission.

Methods: This cross-sectional study was carried out during the period of July 2018 to June 2019 in Bangladesh Institute of Research and Rehabilitation in Diabetes, Endocrine and Metabolic Disorders (BIRDEM) General Hospital, Dhaka, Bangladesh. Cirrhosis of liver was diagnosed mostly with the help of ultrasonography of whole abdomen and endoscopy of upper GIT. In few selected cases fibroscan of liver and liver biopsy were done.

Results: This study included 724 patients who had cirrhosis of liver. Of them 276 cases had viral and 448 cases had non viral causes. We studied among 276 cases who had viral etiology. Male predominated over female (M: $F=2.1: 1)$ at presentation. Male patients were mostly in service (25.7\%) and female patients were housewives (27.5\%). Most of the patients were diabetic (53.3\%), within 41-50 years of age (29.0\%), urban background (67.0\%) and mostly present as compensated than decompensated stage of cirrhosis of liver and it had significant association ( $p$ value .007) with liver cirrhosis. Among viral etiology HBV(70.7\%) is the leading cause of cirrhosis of liver followed by HCV(28.6\%). Both HBV and HCV infections were found more in male than female and it is significantly associated with cirrhosis of liver ( $p$ value .001). HBV infections were found more in non-diabetic patients and it is highly significant (p value .000) but HCV infections were found more in diabetic patients but it is not significant(p value .194). Regarding transmission of virus, male patients gave past history of haircut and shaving in barber shop in 37.76\% cases for HBV, 27.66\% cases for HCV positive patient and for female gave past history of childbirth by midwifery ('dhais') in 36.36\% cases for HBV, 12.5\% cases for $\mathrm{HCV}$ positive patient. In case of HBV transmission, history of surgery (23.14\%), blood transfusion(4.71\%), family history (24.7\%) of HBV and in case of HCV history of surgery(16.47\%), blood transfusion(9.01\%), family history (1.57\%) of HCV were found in both male and female patient. History of high risk exposure to multiple sexual partner were found more in $\mathrm{HBV}$ than $\mathrm{HCV}$ positive male patient.
\end{abstract}

Author Information

a. Dr. Md. Abdullah Al Mamoon, Assistant Professor, Department of Gastrointestinal, Hepatobiliary and Pancreatic Disorders (GHPD), BIRDEM General Hospital, Dhaka, Bangladesh.

b. Dr. Arif Mahmud, Senior Medical Officer, Department of Gastrointestinal, Hepatobiliary and Pancreatic Disorders (GHPD), BIRDEM General Hospital, Dhaka, Bangladesh.

c. Dr. Riad Md Moshaed Hossain, Senior Medical Officer, Department of Gastrointestinal, Hepatobiliary and Pancreatic Disorders (GHPD), BIRDEM General Hospital, Dhaka, Bangladesh.

d. Dr. Shireen Ahmed, Registrar, Department of Gastrointestinal, Hepatobiliary and Pancreatic Disorders (GHPD), BIRDEM General Hospital, Dhaka, Bangladesh.

e. Dr. Sarker Mohammad Sajjad, Registrar, Department of Gastrointestinal, Hepatobiliary and Pancreatic Disorders (GHPD), BIRDEM General Hospital, Dhaka, Bangladesh.

f. Prof. Tareq Mahmud Bhuiyan, Professor, Department of Gastrointestinal, Hepatobiliary and Pancreatic Disorders (GHPD), BIRDEM General Hospital, Dhaka, Bangladesh.

*In this original article both author ' $a$ ' and ' $b$ ' have equal contribution and they are considered as 'first' author.

Address of correspondence: Dr. Md. Abdullah Al Mamoon, Assistant Professor, Department of Gastrointestinal, Hepatobiliary and Pancreatic Disorders(GHPD),BIRDEM General Hospital, Dhaka. Email:mamoonjbdk@gmail.com.

Received: February 13, 2020

Accepted: June 30, 2020 
Conclusion: Cirrhosis of liver is more common in male than female patient between the age of 41-50, mostly urban background and present to us more at compensated stage. HBV infection is more common in male non diabetic and HCV infection is more common in female diabetic patient. Male patients with past history of haircut or shaving in barber shop and for female patient with history of delivery by midwifery ('dhais') more for HBV than HCV compared to history of blood transfusion more for HCV than HBV positive patient had an important role for virus transmission in our country.

Key words: Demography, cirrhosis of liver, viral profiles, modes of transmission.

(BIRDEM Med J 2020; 10(3): 192-199)

\section{Introduction}

Cirrhosis, a final pathway for a wide variety of chronic liver diseases, is a pathologic entity defined as diffuse hepatic fibrosis with the replacement of the normal liver architecture by nodules. The rate of progression of chronic liver disease to cirrhosis may be quite variable, from weeks in patients with complete biliary obstruction to decades in patients with chronic hepatitis C. ${ }^{1}$ Compensated cirrhotic patients have a 50\% 10 year survival as compared to $50 \%$ survival at 18 months for decompensated patients. ${ }^{2}$

The presence of HBsAg establishes the diagnosis of hepatitis B. The prevalence of HBsAg varies greatly across countries, with high prevalence of HBsAgpositive persons defined as $>8 \%$, intermediate as $2 \%$ to $7 \%$, and low as $<2 \% .{ }^{3,4}$ In developed countries, the prevalence is higher among those who immigrated from countries with high- or intermediate prevalence and from countries with high-risk behaviors. ${ }^{4,5}$ Hepatitis $\mathrm{C}$ virus (HCV) infection is one of the main causes of chronic liver disease worldwide. ${ }^{6}$

Bangladesh is in the intermediate prevalence zone of hepatitis B virus (HBV), with a $40 \%$ lifetime risk of acquiring the virus by its residents. Hepatitis $B$ has been extensively studied in Bangladesh. The prevalence of $\mathrm{HBV}$ in Bangladesh is $5.4 \%$ with neonatal, perinatal, and preschool transmission, injectable medications, treatment from quack, mass vaccination against chickenpox and cholera, haircut and shaving at barber shop have been identified as the principal modes of transmission of the virus in the country. ${ }^{7} \mathrm{HCV}$ infection in northern India is seen more commonly in males, middle aged, rural background from low-middle socioeconomic status. The common possible risk factors are dental treatment and exposure to reused syringes and needles. Though the commonest presentation is incidental detection, a large number of patients present with advanced liver disease. ${ }^{8}$

Chronic viral hepatic infections are a major threat to public health worldwide. Chronic hepatitis B virus (HBV) and hepatitis $\mathrm{C}$ virus (HCV) are the leading causes of cirrhosis and hepatocellular carcinoma, two conditions with increasing mortality and burden of disease especially in the developing countries. ${ }^{9}{ }^{910} \mathrm{In}$ western countries, the prevalence of alcoholic cirrhosis, NASH cirrhosis (nonalcoholic steatohepatitis) and viral cirrhosis, in particular hepatitis $\mathrm{C}$, are all increasing. In developing countries, the predominant causes are hepatitis virus $\mathrm{B}$ and $\mathrm{C}$, but alcohol and autoimmune conditions may be increasing. There are approximately 71 million chronically infected individuals worldwide. ${ }^{6,11}$ Many of whom were unaware about their infection, with important variations according to the geographical area. Cirrhosis where the etiology cannot be determined is termed as cryptogenic.

In some forms of liver disease there is a single cause, for example in hepatitis B and C, primary biliary cirrhosis and primary sclerosing cholangitis. However, in many cases co - factors may be important. Suggested co - factors include age, sex, obesity, alcohol, iron intake and other genetic factors as yet unknown.

Patient with history of chronic liver disease with gastro esophageal varices, ascites, or hepatic encephalopathy are likely to have cirrhosis, and liver biopsy is not essential in such cases for confirming cirrhosis. ${ }^{12}$ A small nodular liver with splenomegaly and intra-abdominal collaterals and the presence of ascites on abdominal ultrasonography(or other cross-sectional imaging study) suggests cirrhosis. Where available, transient elastography, acoustic radiation force impulse (ARFI) elastography or magnetic resonance elastography (MRE) can help confirm a diagnosis of cirrhosis. On transient elastography, a liver stiffness measurement (measured in kilopascals) of greater than $14 \mathrm{KPa}$ suggests cirrhosis, with values greater than $21 \mathrm{KPa}$ associated with portal hypertension and its complications. ${ }^{12}$

Liver biopsy has long been the gold standard for diagnosing cirrhosis but may be associated with costs and procedure related risks, albeit infrequently. 
The aim of our study to see the demography and virological profile with their possible modes of transmission in patients with diagnosed case of cirrhosis of liver in our country.

\section{Methods}

This cross-sectional study was carried out from July, 2018 to June, 2019 in BIRDEM General Hospital, Dhaka, Bangladesh. Both indoor and outdoor patients who had established viral causes of cirrhosis of liver were included in our study. Patients who fulfilled the criteria of liver cirrhosis, either compensated or decompensated, irrespective of age were included in this study. Patients who had severe co-morbid disease, known case of hematological malignancy, non-cirrhotic portal hypertension, acute hepatitis $\mathrm{B}$ and $\mathrm{C}$ virus infection, inactive chronic $\mathrm{HBV}$ and $\mathrm{HCV}$, non viral cause of liver cirrhosis and pregnancy were excluded from the study. For data collection, a questionnaire was used. Data were recorded through face to face interview, observation and medical records were reviewed for diagnosed cirrhosis of liver. Ultrasonographic features like coarse hepatic parenchyma, splenomegaly, nodular liver, ascites were used for the diagnosis of cirrhosis of liver. Endoscopic features like esophageal varices, fundal varices, congestive gastropathy, vascular ectasias also guided for the diagnosis of cirrhosis of liver. In selected cases fibrosacn of liver and liver biopsy were done. Laboratory data like presence of HBsAg, anti $\mathrm{HCV}$ were noted. Research protocol was approved by the Ethical Review committee of BIRDEM before commencement of the study. All ethical issues were maintained throughout the study. After collection of information, these data were checked, verified for consistency \& edited for finalized result. After editing the coded data were entered into the computer by using the SPSS (Statistical Package for Social Sciences) version-23.0 software. Data cleaning, validation \& analysis were performed using the SPSS software. Statistical analyses were done by using appropriate statistical tools like $t$-test and chi square test where appropriate. The results were presented in tables with mean, standard deviation (SD) \& percentages. P-value of $<0.05 \%$ was taken as statistically significant.

\section{Results}

During the study period 724 patients with liver cirrhosis were enlisted. Out of them 276 cases had viral and 448 cases had non-viral etiology. We studied only 276 cases of liver cirrhosis who had viral etiology. Most of the patients $(29.0 \%)$ were between the age of $41-50$ and it had significant association with cirrhosis (more at compensated than decompensated stage) of liver ( $p$ value .007). Other baseline demo graph is presented in Table I. Different viral etiology for the development of cirrhosis of liver and their relation with sex and diabetes are presented in Table III, IV, V, VI and VII. Most of the patients were diabetic(53.3\%). Table IV showed both $\mathrm{HBV}$ and $\mathrm{HCV}$ infection were more common in male patient and it had significant association with cirrhosis of liver(p value 0.001). But in relation to diabetes HBV was more common in male, non-diabetic patients and $\mathrm{HCV}$ was more common in female, diabetic patients and it is shown in table VI\&VII. Modes of possible viral transmission is shown in table VIII. Family history of HBV was positive in $24.7 \%$ cases while $\mathrm{HCV}$ was prevalent only in $1.57 \%$ cases.

Table I Demographic characteristics of the study subjects $(\mathrm{N}=276)$

Demographic characteristics Frequency Percentage

Age group (years)

$\begin{array}{lcc}<30 & 30 & 10.9 \\ 31-40 & 43 & 15.6 \\ 41-50 & 80 & 29.0 \\ 51-60 & 67 & 24.3 \\ 61-70 & 44 & 15.9 \\ 71-80 & 10 & 3.6 \\ >80 & 2 & .7 \\ \text { Total } & 276 & 100.0 \\ \text { Mean } \pm \text { SD } & 49.63 \pm 13.52 \\ \text { Range } & (21-90) \text { years }\end{array}$

Sex

Male

Female

88

31.9

Male: Female ratio

2.1:1

Occupation

Business

57

20.7

Service

25.7

Housewife

71

27.5

Others

18.8

Unemployed

7.2

Residence

Urban

185

67.0

Rural

91 
Table II Comparison of age with types of cirrhosis $(\mathrm{N}=276)$

\begin{tabular}{lccc}
\hline Age group & Compensated $(\mathrm{n}=153)$ & Decompensated $(\mathrm{n}=123)$ & p-value \\
\hline$<30$ & No. $(\%)$ & No. $(\%)$ & \\
$31-40$ & $20(13.1 \%)$ & $10(8.1 \%)$ & \\
$41-50$ & $25(16.3 \%)$ & $18(14.6 \%)$ & \\
$51-60$ & $46(30.1 \%)$ & $34(27.6 \%)$ & $0.007^{*}$ \\
$61-70$ & $39(25.5 \%)$ & $28(22.8 \%)$ & \\
$71-80$ & $21(13.7 \%)$ & $23(18.7 \%)$ & \\
$>80$ & $2(1.3 \%)$ & $8(6.5 \%)$ & \\
Total & $0(0.0 \%)$ & $2(1.6 \%)$ & \\
Mean \pm SD & $153(100.0 \%)$ & $123(100.0 \%)$ & \\
Range & $47.7 \pm 12.7$ & $52.1 \pm 14.2$ & \\
\hline
\end{tabular}

Unpaired student t-test, * significant

Table III Distribution of the patients by viral profile in liver cirrhosis $(\mathrm{N}=276)$

\begin{tabular}{lcc}
\hline Viral profile & Frequency & Percentage (\%) \\
\hline HBs Ag +ve & 195 & 70.7 \\
Anti HCV +ve & 79 & 28.6 \\
Both HBs Ag+ve\& Anti HCV +ve & 2 & 0.7 \\
\hline Total & 276 & 100.0 \\
\hline
\end{tabular}

Table IV Relation of the virus with sex $(\mathrm{N}=276)$

\begin{tabular}{lcccc}
\hline Sex & HBsAg+ve & Anti HCV +ve & Both positive & p-value \\
\hline & No. $(\%)$ & No. $(\%)$ & No. $(\%)$ & \\
Male & $145(52.5 \%)$ & $41(14.9 \%)$ & $2(0.70 \%)$ & $0.001 \mathrm{~s}$ \\
Female & $50(18.1 \%)$ & $38(13.8 \%)$ & $0(0.0 \%)$ & \\
\hline Total & $195(70.7 \%)$ & $79(28.6 \%)$ & $2(0.70 \%)$ & \\
\hline
\end{tabular}

Chi-square test, $\mathrm{s}=$ significant

Table V Distribution of the study patients by diabetes mellitus (N=276)

\begin{tabular}{lcc}
\hline Diabetes mellitus $(\mathrm{DM})$ & Frequency & Percentage (\%) \\
\hline Yes & 147 & 53.3 \\
No & 129 & 46.7 \\
\hline Total & 276 & 100.0 \\
\hline
\end{tabular}


Table VI Distribution of the study subject between diabetic and non-diabetic patient with viral profiles $(\mathrm{N}=276)$

\begin{tabular}{lccc}
\hline Viral status & DM & Non-DM & P-value \\
\hline HBs Ag+ve(n=195) & $89(45.64 \%)$ & $106(54.36 \%)$ & .000 \\
Anti HCV+ve(n=79) & $56(70.89 \%)$ & $23(29.11 \%)$ & .194 \\
Both HBsAg and Anti HCV +ve(n=2) & $2(100 \%)$ & $0(0 \%)$ & - \\
\hline
\end{tabular}

Chi-square test, significant for HBV but not significant for HCV

Table VII Distribution of viral profile between diabetic and non-diabetic patients in relation to sex $(\mathrm{N}=276)$.

\begin{tabular}{llccc}
\hline Viral status & Sex & Dresent & Absent & \\
& & $63(32.3 \%)$ & $82(42.1 \%)$ & $0.295 \mathrm{~ns}$ \\
\hline HBs Ag +ve $(\mathrm{n}=195)$ & Male & $26(13.3 \%)$ & $24(12.3 \%)$ & \\
& Female & $27(34.2 \%)$ & $14(17.7 \%)$ & $0.306 \mathrm{~ns}$ \\
Anti-HCV +ve $(\mathrm{n}=79)$ & Male & $29(36.7 \%)$ & $9(11.4 \%)$ & \\
& Female & $2(100.0 \%)$ & $0(0.0 \%)$ & - \\
Both HBsAg and Anti-HCV +ve $(\mathrm{n}=2)$ & Male & $0(0.0 \%)$ & $0(0.0 \%)$ & - \\
& Female & &
\end{tabular}

Chi-square test, ns=not significant

Table VIII Distribution of patients with possible modes of viral transmission ( $\mathrm{N}=276)$

\begin{tabular}{lcccccc}
\hline Modes of possible viral transmission & \multicolumn{2}{c}{$\mathrm{HBs}$ HC+ve } & \multicolumn{3}{c}{ Both +ve } \\
& No. & $\%$ & No. & $\%$ & No. & $\%$ \\
\hline Modes identified (n=255) & & & & & & \\
Blood transfusion & 12 & 4.71 & 23 & 9.01 & 0 & 0.0 \\
IV drug abuse & 0 & 0.0 & 1 & 0.39 & 0 & 0.0 \\
Past history of surgery & 59 & 23.14 & 42 & 16.47 & 0 & 0.0 \\
History of jaundice & 0 & 0.0 & 0 & 0.0 & 0 & 0.0 \\
Multiple high risk sexual exposure in male & 15 & 5.88 & 5 & 1.96 & 2 & 0.7 \\
Shaving/haircut in barber shop in male & 71 & 37.76 & 52 & 27.66 & 1 & 0.4 \\
Shaving privately in male & 16 & 8.51 & 4 & 2.13 & 1 & 0.4 \\
Shaving both(barber shop \& at home) in male & 16 & 8.51 & 19 & 10.10 & 0 & 0.0 \\
Child birth by midwifery('dhais') & 32 & 36.36 & 11 & 12.5 & 0 & 0.0 \\
Family history & & 0.0 & & 0.0 & & 0.0 \\
Jaundice & 0 & 0.0 & 0 & 0.0 & 0 & 0.0 \\
Liver cancer & 1 & 0.39 & 0 & 0.0 & 0 & 0.0 \\
HBs Ag & 63 & 24.71 & 0 & 0.0 & 0 & 0.0 \\
HCV & 0 & 0.0 & 4 & 1.57 & 0 & 0.0 \\
Liver disease(not specified) & 4 & 1.57 & 0 & 0.0 & 0 & 0.0 \\
CLD & 0 & 0.0 & 0 & 0.0 & 0 & 0.0 \\
HBs Ag and HCC & 1 & 0.39 & 0 & 0.0 & 0 & 0.0 \\
\hline
\end{tabular}

Modes not identified ( $\mathrm{N}=21)$

(IV-Intravenous, HCC- Hepatocellular carcinoma, CLD-Chronic liver disease) 


\section{Discussion}

Liver cirrhosis, a final pathway for a wide variety of chronic liver diseases, is a lifelong disease. It is an important cause of mortality and morbidity in our country. Due to lack of adequate knowledge and awareness about the route of entry or modes of transmission of viruses, their natural history with tendency of patients to choose their specialists by their self-judgment and absence of referral system in our country many patients suffer from this type of liver injury.

In this study out of 724 patients only 276 cases of virological cause of cirrhosis of liver were studied. Most of the patients were between the age of 41-50(29.0\%), male (M:F-2.1:1), urban background (67\%), diabetic $(53.3 \%)$ and present to their physician at compensated state of liver cirrhosis. Memon et $\mathrm{al}^{13}$ also showed advancing age $\geq 40$ years in HCV seropositive patients with cirrhosis of liver was significantly associated with type 2 diabetes mellitus. Our study also matched with another study which was done in Mexican population. ${ }^{22}$ Most of the male patients were in service $(25.7 \%)$ and female patients were housewives (27.5\%).

Our study showed that both hepatitis B and C virus is mostly responsible for the cirrhosis of liver in male (p value .001) patient but in relation to diabetes, $\mathrm{HBV}$ is more common in male, non-diabetic and HCV is more common in female, diabetic patients. Bangladesh, together with the Indian sub-continent, is recognized as a country with moderate prevalence of hepatitis B. ${ }^{7}$ Mamun Al Mahtab et all ${ }^{7,14}$ showed that, in our country seroprevalence of hepatitis B is $5.5 \%$ and for hepatitis $\mathrm{C}$ is $.88 \%$. So in this relation in general population of our country hepatitis B is 6.25 times more common than hepatitis $\mathrm{C}$. In general population of our country due to the high prevalence of hepatitis B than hepatitis C, chance of liver cirrhosis due to $\mathrm{HBV}$ is more than HCV. Our study revealed that among liver cirrhotic patient not in general population hepatitis B $(70.7 \%)$ is the predominant cause (only 2.47 times than hepatitis $\mathrm{C}$ in liver cirrhotic patient instead of 6.25 times in general population) of liver cirrhosis followed by Hepatitis $\mathrm{C}$ (28.6\%). Das DC etal ${ }^{16}$ also showed hepatitis B virus is the leading cause of cirrhosis of liver in Bangladesh. If we compare seroprevalence of $\mathrm{HBV}$ and $\mathrm{HCV}$ virus in general population with $\mathrm{HBV}$ and $\mathrm{HCV}$ virus in liver cirrhotic patients it was clearly evident that though the prevalence of hepatitis B is 6.25 times more than hepatitis $\mathrm{C}$ in general population, proportionately hepatitis $B$ virus was not found in liver cirrhotic patients which was only 2.47 times more than $\mathrm{HCV}$. In fact hepatitis $\mathrm{C}$ virus was more found in liver cirrhotic patients due to its high chance of chronicity. ${ }^{17}$ This study also showed HCV is more common in female diabetic patients and $\mathrm{HBV}$ is more in male non diabetic patients. Mamoon et all ${ }^{21}$ also showed that hepatitis $\mathrm{C}$ virus is the main cause of cirrhosis of liver in female diabetic patient. This difference was probably due to our study was conducted in diabetes centre, they were mostly diabetic and in diabetic patient hepatitis $\mathrm{C}$ virus is more common. ${ }^{19}$ Chance of chronicity of $\mathrm{HCV}$ is more than $\mathrm{HBV}$ also an important contributing factor. The rate of chronic HBV infection varies from 0.1 to $20 \%$ in different areas of the world. ${ }^{18}$ In intermediate prevalence areas such as the Mediterranean countries, Eastern Europe, India, Bangladesh and Singapore, the rate is approximately 3 to $5 \%$.In chronic HBV infections, chance of development of liver cirrhosis is $2-10 \%{ }^{15}$ For hepatitis C, $75-85 \%$ cases turn to chronic infection and among them liver cirrhosis develops in about 10 $20 \%$ of patients within 20 years of age. ${ }^{17}$

In this study the most important possible risk factor for viral transmission in male patient had past history of haircut and shaving in barber shop in $37.76 \%$ cases for HBV, $27.66 \%$ cases for HCV positive patient and in case of female patients had past history of childbirth by midwifery ('dhai') in $36.36 \%$ cases for HBV, $12.5 \%$ cases for $\mathrm{HCV}$ positive patient. For both male and female patient, in case of HBV history of surgery (23.14\%), blood transfusion (4.71\%), positive family history $(24.7 \%)$ and in case of HCV history of surgery (16.47\%), blood transfusion $(9.01 \%)$, positive family history $(1.57 \%)$ were found. So care should be needed before one goes to barber shop for hair cut or shaving and surgery for the prevention of possible routes of viral transmission. Mahtab MA et all ${ }^{14}$ showed shaving or hair cut in barber shop had a significant role for HCV transmission. But our study showed that this association is more prevalent in HBV than HCV. Most of the people do not know the consequences of childbirth at home both for the fetus and mother. So educating the people properly regarding the importance of sterilization and fatal outcome of childbirth at home is highly sought. Screening must be ensured before blood transfusion and 
at the same time, professional blood donors should be discouraged. Our study showed that vertical transmission for hepatitis B is 15.75 times more than hepatitis $\mathrm{C}$. So all pregnant women should be screened for the presence of HBV. Obstetrician and/or pediatrician should be encouraged to discuss with pregnant women with HBV positivity to take measure for the prevention of mother-to-child transmission of $\mathrm{HBV}$. Since vaccination against HBV is available in our country, following child birth of HBV positive mother, hepatitis B immune globulin (HBIG) and HBV vaccine should be administered to their newborn baby within 12 hours of delivery. ${ }^{5,20}$ High risk sexual exposure with multiple sexual partner probably had some role for viral transmission. So people should be educated properly about the health hazard of high risk multiple sexual relationship with social and religious bindings.

The study carried out in a tertiary care hospital, BIRDEM, may not be a true representative picture of the whole country, since our patients were mostly diabetic and they lived mostly in urban areas.

\section{Conclusion}

Cirrhosis of liver is more common in male than female patient between the age of 41-50, mostly urban background and present to us predominantly at compensated stage. HBV infection is more common in male non diabetic and HCV infection is more common in female diabetic patient. Shaving or hair cut in barber shop, child birth by midwifery ('dhais'), surgery, blood and blood product transfusion, vertical transmission had an important possible modes of viral transmission in our country. Health awareness and education programs may help to prevent the development of liver cirrhosis and its complication. Patient should be educated properly regarding the likely viral causes of liver cirrhosis with their modes of transmission, importance of vaccination against $\mathrm{HBV}$, screened blood and blood product transfusion, use of disposable syringe, surgical instrument, blade, shaving instrument and importance of childbirth at hospital.

Conflict of interest: Nothing to declare.

\section{References}

1. Kamath PS and Shah VH. Overview of cirrhosis. In: Feldman M, Friedman LS and Brandt LJ (Eds).Sleisenger and Fordtran's Gastrointestinal and Liver Disease.10th edition. Philadelphia: Elsevier ; 2016.p 1254.
2. Gines P, Quintero E, Arroyo V, Teres J, Bruguera M, Rimola A, et al. Compensated cirrhosis: Natural history and prognostic factors . Hepatology 1987; 7(1):122-28.

3. Lavanchy D. Hepatitis B virus epidemiology, disease burden, treatment, and current and emerging prevention and control measures. J Viral Hepat 2004; 11: 97-107.

4. Nelson NP, Easterbrook PJ, McMahon BJ. Epidemiology of Hepatitis B Virus Infection and Impact of Vaccination on Disease. Clin Liver Dis 2016; 20:607-28.

5. Weinbaum CM, Williams I, Mast EE, Wang SA, Finelli L, Wasley A, et al. Recommendations for identification and public health management of persons with chronic hepatitis B virus infection. MMWR Recomm Rep 2008; 57:1-20.

6. Polaris Observatory HCV Collaborators. Global Prevalence and Genotype Distribution of Hepatitis C virus infection in 2015: A modelling study. Lancet Gastroenterol Hepatol 2017; 2:161-76.

7. Mahtab MA, Rahman S, Karim MF, Khan M, Foster G, Solaiman S, et al. Epidemiology of hepatitis B virus in Bangladeshi General Population. Hepatobiliary Pancreat Dis Int. 2008; 7(6): 595-600.

8. Mahajan R, Midha V, Goyal O, Mehta V, Narang V, Kaur K, et al. Clinical profile of hepatitis $\mathrm{C}$ virus infection in a developing country-India J Gastroenterol Hepatol. 2017 Sep 18. doi: 10.1111/jgh.13995.

9. Mokdad AA, Lopez AD, Shahraz S, Lozano R, Mokdad AH, Stanaway J, et al. Liver cirrhosis mortality in 187 countries between 1980 and 2010: a systematic analysis. BMC Med, 2014; $12: 145$.

10. Mittal S, Serag HB. Epidemiology of Hepatocellular Carcinoma: Consider the population. J Clin Gastroenterol. 2013 jul; 47(Suppl 0): S2-6.

11. European Union HCV Collaborators. Hepatitis C virus prevalence and level of intervention required to achieve the WHO targets for elimination in the European Union by 2030: a modelling study. Lancet Gastroenterol Hepatol. 2017; 2: 325-36.

12. Robic MA, Procopet B, Metivier S, Peron JM, Selves J, Vinel $\mathrm{JP}$, et al. Liver stiffness accurately predicts portal hypertension related complications in patients with chronic liver disease. A prospective study. J Hepatol 2011; 55(5):1017-24.

13. Memon MS, Arain ZI, Naz F, Zaki M, Kumar S, Burney AA. Prevalence of Type 2 Diabetes Mellitus in Hepatitis C Virus Infected Population: a Southeast Asian Study; Journal of Diabetes Research.2013;2013:539361

14. Mahtab MA, Rahman S, Karim F, Foster G, Solaiman S. Epidemiology of Hepatitis C Virus in Bangladeshi General Population. BSMMU J 2009; 2(1):14-17.

15. Lok ASF. Hepatitis B. In: Dooley JS, Lok ASF, Burroughs AK, Heathcote EJ (Eds). Sherlock's Diseases of the Liver and Biliary System.13th edition. Oxford, UK: WileyBlackwell; 2018.p 395-20. 
16. Das DC, Mahtab MA, Rahim MA, Malakar D, Kabir A, Rahman S. Hepatitis B virus remains the leading cause of cirrhosis of liver in Bangladesh. Bangladesh Med J 2016 Sep; 45(3).

17. Chen SL, Morgan TR. The natural history of hepatitis $C$ virus (HCV) infection. Int.J. Med. Sci. 2006; 3:47-52.

18. Lavanchy D. Hepatitis B virus epidemiology, disease burden, treatment, and current and emerging prevention and control measures .J. Viral Hepatol .2004 ;11: 97-107 .

19. Lonardo A, Adinolfi LE, Petta S, Craxi A, Loria P. Hepatitis $\mathrm{C}$ and diabetes: the inevitable coincidence? Expert Rev Anti Infect Ther. 2009 Apr ;7(3):293-308.
20. Mast EE, Weinbaum CM, Fiore AE, Alter MJ, Bell BP, Finelli $\mathrm{L}$, et al. A comprehensive immunization strategy to eliminate transmission of hepatitis B virus infection in the United States: recommendations of the Advisory Committee on immunization Practices (ACIP) Part II: immunization of adults. MMWR Recomm Rep 2006; 55:1-33.

21. Mamoon AA, Bhuiyan TM, Azam MG, Hoque MN, Hossain RMM. Comparison of demographic and virological profiles between diabetic and non-diabetic patients with cirrhosis of liver. BIRDEM Med J 2019; 9(3): 229-33.

22. Chiquete E, Guzman AO, Lamas LG, Gomez FA, Manjarrez JIG, Orozco LVS, et al. Hepatitis C virus infection and type 2 diabetes mellitus in Mexican patients. Revista Medica del instituto Mexicano del Seguro Social 2012; 50(5):481-86. 